\title{
Produção audiovisual e história oral - Notas sobre a cafeicultura nas imagens de Armínio Kaiser
}

\section{Tati Lourenço da Costa' Daniel Choma ${ }^{2}$}

Neste espaço, propomo-nos a discutir a experiência do projeto audiovisual "Grãos de ouro em sais de prata", em que realizamos documentários a partir das imagens fotográficas produzidas pelas lentes de Armínio Kaiser. As imagens registram o período de 1957 a 1970, quando Kaiser atuou como técnico do Instituto Brasileiro do Café, lotado no estado do Paraná. Desde 2007, desenvolvemos pesquisas fotográficas com o riquíssimo acervo do autor, até então inédito. Inicialmente, realizamos a higienização, a organização e a digitalização para a salvaguarda dos originais, e açôes de difusão das imagens através de publicaçôes. O contato com o fotógrafo e as informaçóes de seus registros fotográficos sobre a cafeicultura inspirou, em 2008, uma pesquisa audiovisual junto a trabalhadores e ex-trabalhadores do café, a fim de registrar quais narrativas seriam construídas em torno das fotografias de Armínio Kaiser. Questionávamos: que segredos estariam latentes nas fotografias de Armínio Kaiser? Quais memórias elas conteriam? Que sonhos elas teriam sonhado a respeito de seus futuros, como sugere Mauricio Lissovsky

1 Doutoranda em História na Universidade Federal de Santa Catarina (e-mail: tatilcosta@yahoo.com.br).

2 Mestre em História pela Universidade do Estado de Santa Catarina e especialista em Fotografia pela Universidade Estadual de Londrina (e-mail: danielchoma@yahoo.com.br). 
(2008) ao se perguntar o que fazem as fotografias quando não estamos olhando para elas? 3 .

\section{O personagem}

Armínio Kaiser nasceu em Salvador, no ano de 1925. Sua história tem raízes antigas na fotografia: o avô, Manoel Gonsalvez da Silva, era fotógrafo, ainda no século XIX, no Nordeste brasileiro, sendo verbete do dicionário histórico-fotográfico brasileiro: "Foi itinerante por várias províncias do Nordeste. A primeira referência à sua atividade é registrada em Feira de Santana, no ano de 1877, quando divulgada por um periódico local a 'photographia glacê [...] o mais bello systema de retratos'”. (Kossoy, 2002). Foi remexendo o velho baú do avô que Kaiser descobriu a fotografia. Diz ele: "Mergulhei na magia da fotografia: congelamento de um instante do tempo" (Kaiser, 2008, p.144).

Em 1953, recém-formado engenheiro agrônomo, Armínio ingressou no Instituto Brasileiro do Café - IBC, no estado de Sáo Paulo, onde trabalhou entre 1953 e 1989, tendo sido transferido para o Paraná em 1957, a fim de incentivar o controle da erosão que assolava a região de Paranavaí. Paralelamente ao trabalho técnico, Kaiser foi construindo sua própria leitura das mudanças sociais que vivenciava através da fotografia. Com sua companheira em mãos e olhar social, seus recortes são um exaustivo exercício de composição.

Percorreu inúmeras fazendas e pequenas propriedades, prestando assessoria técnica aos cafeicultores. Sempre carregava consigo uma, duas ou até quatro de suas câmeras fotográficas (de filmes formato $6 \times 6 \mathrm{~cm}$ e $35 \mathrm{~mm}$ ), mais por gosto pessoal que em funçáo de sua profissão. Suas fotografias registram as diversas etapas do trabalho e o drama cotidiano de homens e mulheres que trilharam suas vidas nos caminhos do café.

3 O autor sugere "É graças às suas lacunas que os arquivos ainda nos olham. Todo 'achado' historiográfico é um olhar correspondido que atravessa as eras, o reencontro de um porvir que o passado sonhara - e que somente o nosso próprio sonho de futuro permite vislumbrar" (Lissovsky, 2008, p.2). 
Ao longo dos anos, Kaiser reuniu uma vasta produção sobre as etapas do cultivo do café em diferentes regióes do Brasil, principalmente Sáo Paulo e Paraná; em menor escala, Bahia, Rio de Janeiro e Minas Gerais. No caso da cafeicultura paranaense, ele guardou mais de três mil originais, que ficaram inéditos durante sessenta anos. Trata-se de um acervo de significativa relevância no panorama das pesquisas sobre história da cafeicultura, quando observamos o repertório de fontes fotográficas sobre o café, em que pouco se encontra a respeito do Paraná no século XX.

As fotografias revelam cenas cotidianas da vida nas comunidades rurais do interior do Paraná, um estado em processo de urbanização e em busca da "modernidade". São primorosos registros e permitem visualizar desde a queimada e derrubada de árvores em terras inexploradas até o preparo da terra para plantio. As etapas do cultivo aparecem com detalhes: dos viveiros à cova; da florada à colheita; da secagem e transporte à classificação e armazenagem. Trazem para perto de quem as contempla o cotidiano nas colônias de trabalhadores - casas, bares, famílias, lavadeiras no rio. Boiada na estrada, escola, procissão, estilingue. Revelam a tragédia da erosão em terras arenosas de Paranavaí, a devastação dos cafeeiros pelas geadas, os efeitos do grande incêndio rural de 1963. Múltiplas reminiscências do que Armínio denominou de desassossego - a miséria e o êxodo rural enfrentados por muitos trabalhadores após a erradicação de grande parte das lavouras de café na região norte do Paraná.

O trabalho com o acervo de Armínio Kaiser ${ }^{4}$, sempre em companhia do fotógrafo, além da prática arquivística, está envolvido por um valioso processo reflexivo acerca das políticas agrícolas, das tecnologias de cultivo, dos meios de escoamento e do comércio da produção, das condiçóes de vida dos trabalhadores rurais e, traz, ainda, informaçóes sobre degradação ambiental e êxodo rural.

4 As açốes têm sido realizadas através de projetos culturais, graças aos modestos, porém fundamentais, aportes de leis locais de incentivo à cultura da Prefeitura de Londrina (PROMIC) e do Governo do Estado de São Paulo (PROAC). 


\section{Imagens em movimento}

Entre maio e setembro de 2008, a equipe audiovisual ${ }^{5}$ percorreu quatro distritos da zona rural de Londrina-PR: São Luiz, Patrimônio Regina, Paiquerê e Espírito Santo - a pesquisar e registrar histórias do cotidiano do trabalho com a cafeicultura a partir das narrativas e memórias de trabalhadores e ex-trabalhadores. $\mathrm{O}$ contato com as comunidades deu-se a partir de escolas públicas locais, diretamente com as professoras do curso de Alfabetização do Ensino de Jovens e Adultos (EJA). Essas turmas costumam ser majoritariamente compostas por idosos, e buscávamos dialogar com pessoas que viveram sua juventude por volta das décadas de 1950 e 1960, período em que o fotógrafo Armínio Kaiser realizou seus registros nas lavouras de café.

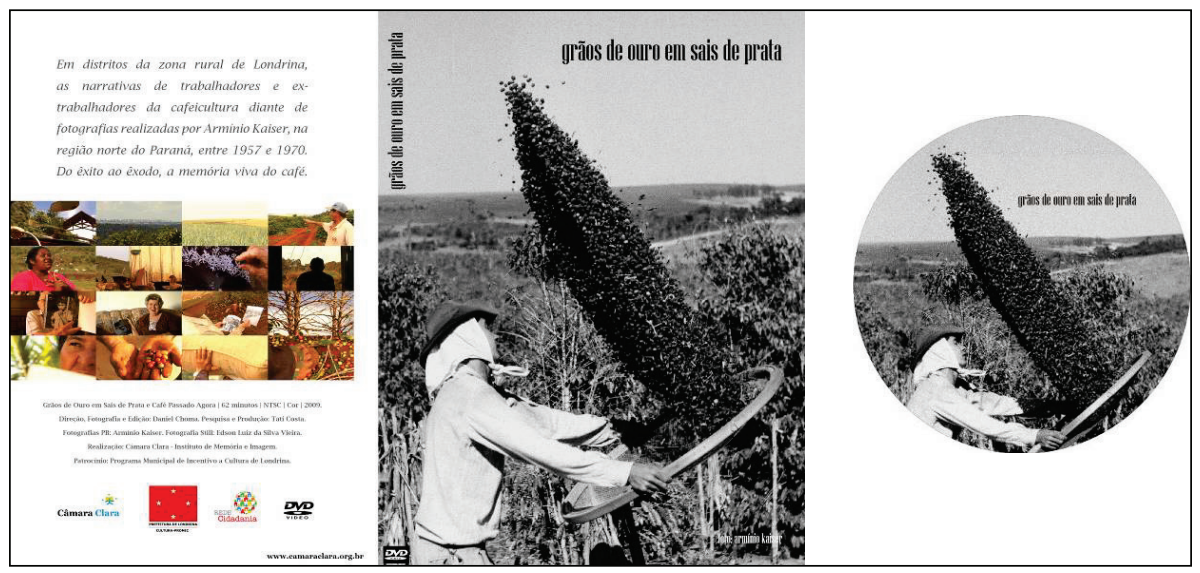

Capa do DVD com os documentários

Grãos de ouro em sais de prata e Café passado agora.

Acesso ao documentário Café Passado

Agora em http://camaraclara.org.br/videos 11 cafe_passado_agora.htm

A parceria com a modalidade de Ensino de Jovens e Adultos foi fundamental ao projeto como espaço de inserção nas comunidades e como pesquisa

5 A equipe do projeto Grãos de ouro em sais de prata: memórias do café foi composta por Daniel Choma, Tati Costa e Edson Vieira. 
do público-alvo potencial para o documentário, pois, entre os estudantes da EJA, existe alto índice de pessoas com idade superior a 50 anos, que não tiveram oportunidade de estudo na infância. Na maioria das vezes, a baixa escolaridade ali está associada ao trabalho e à infância vivida na roça.
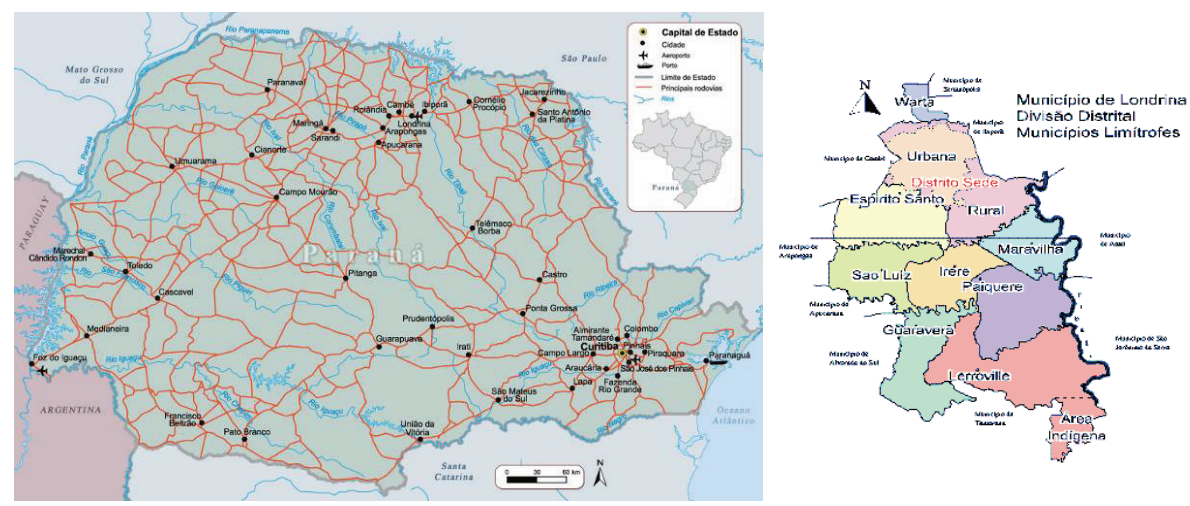

Londrina situa-se na região norte do estado do Paraná. Abaixo, o município com indicação da divisão distrital.

As fotografias de maior potencial expressivo do acervo de Armínio Kaiser foram selecionadas para serem utilizadas como fonte e ferramenta de pesquisa nas entrevistas. A participação do fotógrafo nesse processo, em duas conversas a respeito das circunstâncias e memórias que envolviam as imagens escolhidas, foi fundamental para nos situar a respeito dos contextos cotidianos referentes aos registros das imagens, bem como das técnicas relacionadas à cafeicultura. De cada imagem, foram ampliadas duas cópias, em papel fotográfico tamanho $20 \times 30 \mathrm{~cm}$, coladas pelo verso, de modo que tanto a frente quanto o verso da imagem deixavam visíveis a mesma fotografia. Tal estratégia garante, no momento da filmagem da entrevista, que a imagem possa ser vista duplamente, tanto pela pessoa depoente, que olha e narra sobre a imagem, quanto pela equipe, que entrevista e registra em vídeo. Isso é extremamente importante para garantir a compreensão da narrativa, considerando-se o aspecto dialógico que é marcante na associação entre fotografias e história oral. Quando o observador olha para a imagem, esta desperta nele lembranças, impressóes, sensaçóes. Ao mesmo tempo em que a imagem oferece elementos para despertar a fala, a orali- 
dade, também oferece novas formas de olhar para a imagem. Falar sobre a imagem costuma ser, em grande medida, falar de si. Daí que, no jogo de Didi-Huberman com as palavras, "O que vemos, o que nos olha" (1998), existe uma dialética na imagem.

O roteiro semiestruturado da entrevista contava com um conjunto de 139 fotografias, agrupadas por treze sessões temáticas: derrubada, viveiros, plantio, cultivo, florada, colheita, secagem, armazenagem, geada, erosão, incêndio de 1963, erradicação, cotidiano. Cada categoria possuía um envelope próprio, contendo cerca de dez imagens em seu interior e uma imagem-chave em seu exterior. Predominou um maior número de fotos nas categorias "plantio", "cultivo" e "colheita", por se buscar um detalhamento completo dessas etapas do trabalho com o café.

Com a importantíssima colaboração das professoras da EJA, visitamos as turmas durante o horário de aula, realizando atividades interativas em grupo a partir de rodas de histórias com as fotografias da pesquisa. Em seguida, foram agendadas entrevistas individuais com as pessoas que se mostraram interessadas em colaborar no documentário. A maioria das entrevistas individuais foi realizada nas residências dos colaboradores, e uma delas foi realizada na escola. Entre os distritos, São Luiz foi onde se concentrou a maioria das entrevistas, pelo motivo de ser ali o local em que a cafeicultura ainda se apresenta como principal motor da economia. Coincidentemente, foi lá também que se encontrou a maior turma de idosos em processo de alfabetização presente ao Ensino de Jovens e Adultos (EJA).

A entrevista iniciava-se por uma breve trajetória biográfica, seguida pela apresentação das fotografias. Em princípio, era mostrada apenas uma imagem isolada da categoria temática, entâo, conforme o entrevistado manifestava maior identificação com um determinado tema, esse envelope era aberto e as fotografias inclusas nele melhor investigadas. Com cada um dos entrevistados foram percorridas as treze categorias temáticas, dando-se maior ênfase em algum ponto específico conforme o grau de identificação do entrevistado com tal ponto.

As fotografias, utilizadas como estratégia de aproximação em campo e recurso motivador de narrativas, traziam imagens de um passado distante meio século e despertavam um interessante e produtivo jogo de temporalidades no encontro das imagens com a oralidade. Nota-se que a construção 
narrativa de cada pessoa costuma ser afirmativa durante as entrevistas, a não ser em momentos de insegurança e abalo psicológico por parte do entrevistado. Mas, acima de tudo, não se trata de um discurso pronto, preparado de antemão, e sim de uma composição que se faz no presente.

Durante as gravaçóes, conhecemos novos colaboradores a partir de conversas informais com as pessoas do lugar. Por esse processo de identificação e indicação, realizamos um mapeamento de redes de sociabilidade, personagens e "lugares-chave" para o documentário, e notamos a existência de um fluxo comunitário de proximidade entre os distritos, mesmo que distanciados por quilômetros de lavoura. A seguir, apresentamos uma tabela para oferecer um panorama a respeito das pessoas colaboradoras da pesquisa:

TABELA 1

Lista de entrevistados na pesquisa

\begin{tabular}{|l|l|l|}
\hline \multicolumn{1}{|c|}{ Entrevistados } & \multicolumn{1}{|c|}{ Atividade atual } & \multicolumn{1}{c|}{ Local da entrevista } \\
\hline Armínio Kaiser & Agrônomo aposentado & Área urbana de Londrina \\
\hline Marina Feltrin Ricci & Do lar & Área urbana de Londrina \\
\hline Ademir Turini & Cafeicultor & Distrito Espírito Santo \\
\hline Otacílio João Duarte & Prestador de serviços & Distrito Espírito Santo \\
\hline Francisco Pieroli & Prestador de serviços & Distrito Espírito Santo \\
\hline Raphael Magro & Cafeicultor aposentado & Patrimônio Regina \\
\hline João Jerci Tercioti (Jerson) & Cafeicultor aposentado & Patrimônio Regina \\
\hline Lucia Helena do Nascimento & Boia-fria & Distrito de Paiquerê \\
\hline Sebastiana Rosa Marques & Arrendatária & Distrito de Sáo Luiz \\
\hline Realino Marques & Arrendatário & Distrito de Sáo Luiz \\
\hline Elza Maria dos Santos Rosa & Boia-fria & Distrito de São Luiz \\
\hline Antônia Aparecida da Silva & Caseira & Distrito de São Luiz \\
\hline Jeni Antônio da Silva & Caseiro & Distrito de São Luiz \\
\hline Castorina Matias da Cruz & Boia-fria & Distrito de São Luiz \\
\hline João Jacinto de Morais & Boia-fria & Distrito de São Luiz \\
\hline Estevam Gomes da Silva Filho & Arrendatário & Distrito de São Luiz \\
\hline Osmar da Silva Cruz (Marinho) & Boia-fria & Distrito de São Luiz \\
\hline
\end{tabular}


Além das escolas, a equipe visitou espaços significativos das comunidades e registrou o cotidiano de vilas, sítios e fazendas que produzem café. $\mathrm{Na}$ época da colheita, presenciamos as diversas etapas de trabalho, que envolvem colher, rastelar, abanar, ensacar, carregar, espalhar e secar no terreirão, ensacar novamente e repassar para beneficiamento. Em São Luiz, conhecemos a única máquina de beneficiamento da regiáo, um importante espaço para as etapas de processamento e armazenagem do café.

$\mathrm{Na}$ relação entre o contemporâneo e as imagens registradas por Armínio Kaiser, notamos várias permanências, principalmente em relação às técnicas de cultivo. Dentre as mudanças, que se apresentam muito sutis em termos imagéticos, mas claramente indicadas pelos narradores, destaca-se a forma de plantio dos cafeeiros. Antigamente plantados com maior espaçamento entre si, os cafeeiros podiam se desenvolver para árvores maiores e permitiam o cultivo de subsistência nas "ruas", nos espaços entre os alinhamentos de cafeeiros. Atualmente, o plantio chamado de adensado busca maior produtividade e os pés são plantados mais próximos uns dos outros, sendo também espécies que se desenvolvem como árvores menores e, por estarem bem próximos entre si, não permitem espaço para culturas intercalares de subsistência. Essa mudança reflete-se no cotidiano dos trabalhadores: antigamente podiam colher alimentos da mesma terra onde trabalhavam no café, agora precisam comprá-los.

À supressão das lavouras intercalares de subsistência, está relacionada outra significativa ruptura: as relaçôes de trabalho. $\mathrm{Na}$ época dos registros de Armínio Kaiser, era frequente o colonato nas fazendas de café, quando as pessoas viviam e trabalhavam no sítio ou fazenda, recebendo por porcentagem produzida e mantendo um vínculo com a propriedade durante todo o ano e em todas as etapas da lavoura (plantio, colheita, manutençáo dos cafeeiros ao longo do período até nova colheita). Atualmente, se o trabalhador não é o proprietário da terra, o trabalho é assalariado, de caráter diarista (os boias-frias), concentrado apenas no período produtivo.

Podemos inferir que vários dos processos registrados por Armínio Kaiser - do plantio à erradicação - não findaram em 1970; em algumas áreas, como nos distritos de São Luiz, Paiquerê e Patrimônio Regina, o café ainda é viável em pequenas propriedades, envolve famílias, é parte viva da realidade social. Isso ocorre com menor frequência no distrito do Espírito Santo que, pela maior proximidade com áreas nobres de Londrina, tem 
assistido a um acelerado processo de ocupação imobiliária. De qualquer modo, todos os distritos ainda têm na cafeicultura uma de suas principais economias, e assistem atualmente à erradicação progressiva dos cafezais e à substituição por lavouras mecanizadas (trigo, milho, soja), pecuária ou condomínios residenciais.

Tais aspectos da contemporaneidade foram levados em consideração na etapa seguinte do projeto, da edição e composição do documentário e dos materiais resultantes. Depois de um mês de produção, possuíamos mais de 40 horas registradas em fitas Mini-DV entre entrevistas, paisagens, cotidiano de trabalho. A primeira etapa da edição opera já no momento da transferência das imagens para a ilha de edição. A seletividade inicial dá preferência aos trechos com maior qualidade técnica e estética, além das significâncias temáticas identificadas durante a pesquisa e a produção. Essa fase ocupou três meses de dedicação exclusiva do editor. A seguir, mais três meses foram dedicados à composição narrativa do documentário, que envolve roteirização, edição de imagens, trilha sonora e créditos. Com uma versão inicial do documentário, retornamos às comunidades para gravaçóes complementares, que resultaram em mais 10 horas de registros audiovisuais. Como horizonte de expectativas, buscou-se dar conta das diferenças percebidas durante a pesquisa, transportadas para a narrativa audiovisual.

O resultado foi finalizado em um documentário de 52 minutos de duração, intitulado Grãos de ouro em sais de prata. Ainda, em consideração às dinâmicas dos variados circuitos de difusão, inclusive levando em conta seu potencial uso em salas de aula, foi trabalhada uma reedição para o formato 10 minutos, intitulada Café passado agora.

Para veiculação, foi organizado um livro/DVD, cuja parte textual incorpora trechos das entrevistas transcritas, combinadas com algumas notas registradas por Armínio Kaiser na época de produção das fotografias. No livro, constam as fotografias utilizadas na pesquisa e registros da produção audiovisual. O conteúdo está disponível para download na Internet. 600 exemplares do livro/DVD foram impressos para distribuição nos seguintes circuitos: bibliotecas públicas; escolas (especialmente colégios rurais e agrícolas); bibliotecas, videotecas e centros de documentação universitários; cineclubes e circuitos de cinema e vídeo; televisóes; outras instituiçóes museais ou ligadas à história do café. O projeto audiovisual proporcionou à cidade de Londrina um relevante registro das relaçóes tecidas entre o trabalho e o cotidiano. Para 
além do universo local, transpóe fronteiras na medida em que representa um registro a respeito da trajetória histórica da cafeicultura na região.

A equipe retornou às quatro comunidades - escolas locais e grupos de convivência de idosos - e realizou um total de 28 exibiçóes dos documentários resultantes, como forma de feedback e difusão dos resultados da pesquisa, além da entrega de um exemplar do livro/DVD a cada entrevistado. O reencontro é, sem dúvida, o momento mais gratificante, quando os entrevistados se veem na projeção, seus netos e vizinhos os reconhecem, novas memórias são reveladas e comentadas durante a exibição, que se transforma num evento social, um evento histórico para aquela comunidade.

Transcorridos mais de três anos desde o lançamento, seguimos coletando retornos que nos motivam a considerar a importância educativa dos produtos audiovisuais. O curta Café passado agora já foi exibido na TV SESC e no Canal Futura. A TV Escola, mantida pelo Ministério da Educação, selecionou o documentário de 52 minutos para sua grade de exibiçóes, elaborou uma proposta de abordagem pedagógica desse audiovisual para as séries finais do ensino fundamental, associado ao currículo de História e a temáticas afins de Geografia e Diversidade Cultural ${ }^{6}$. Com uma duração de oito aulas, a atividade aproveita a exibição do vídeo para a exploração dos temas da economia cafeeira, assim como as interfaces entre memória e história e a valorização de temáticas de história regional. No âmbito acadêmico, pesquisas sobre o acervo foram objeto das dissertaçóes de Daniel Choma e Edson Vieira, na área de História e de Comunicação Visual, em 2010. A seguir, imagens das exibiçôes e entrega das cópias do Livro/DVD no distrito de São Luiz.

6 Disponível na sessão "Dicas pedagógicas", do site http://tvescola.mec.gov.br 

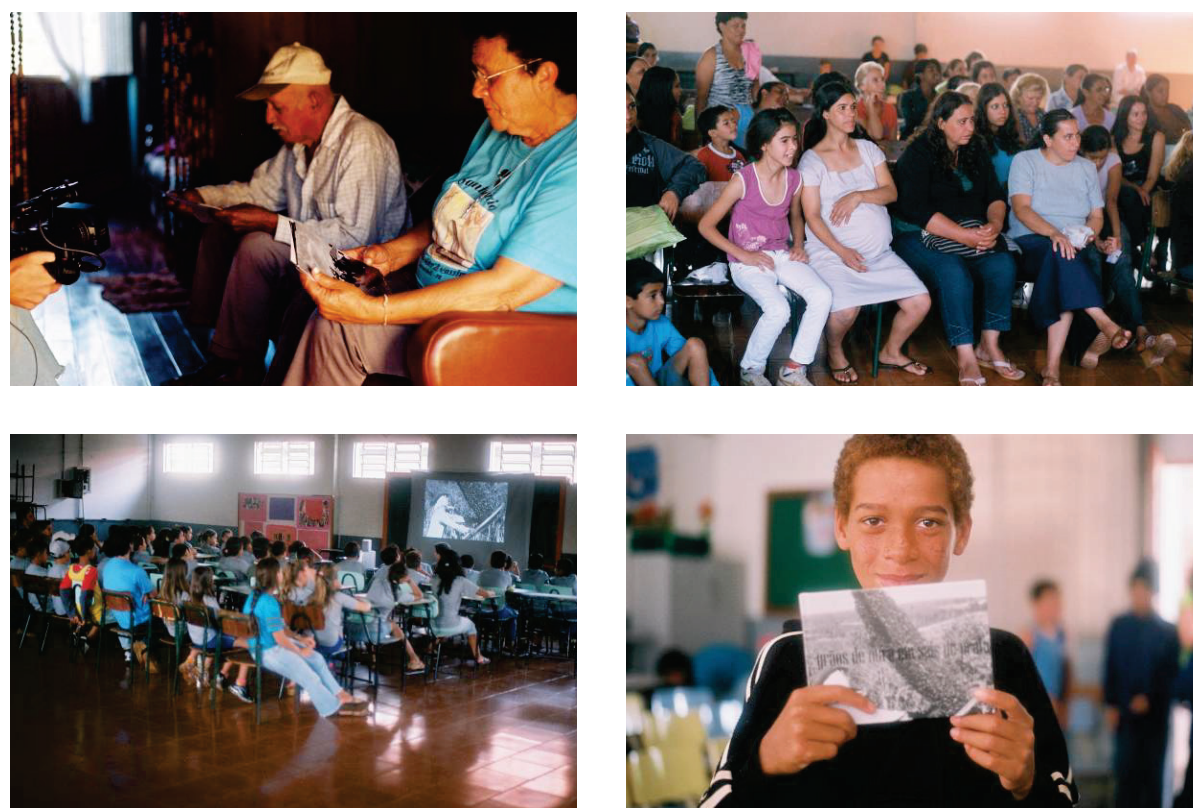

Distrito de São Luiz, área rural de Londrina, PR. Abril/2008.

Fotos: Daniel Choma.

\section{Imagens fixas, memórias flutuantes}

A partir das mesmas fotografias, diferentes narrativas se construíram. Plantio, florada, colheita, lides cotidianas, secagem, procissão, o incêndio de 1963, geadas revelaram-se marcos comuns a todas as narrativas. Mas o modo de abordagem variou. Michel Pollak, a respeito das histórias de vida, observa: "Se destacarmos essa característica flutuante, mutável, da memória, tanto individual quanto coletiva, devemos lembrar também que na maioria das memórias existem marcos ou pontos relativamente invariantes, imutáveis." (Pollak, 1992, 202). Constatou-se que pessoas que ainda trabalham no café construíram narrativas mais técnicas e explicativas em torno das fotografias, enquanto ex-trabalhadores teceram narrativas sensíveis, com lembranças de maior intensidade afetiva. Outro dado de diferença apresentou-se no local de residência atual. A conversa com pessoas que residem na área urbana, portanto distanciadas do cotidiano da roça, revelou ricas informaçóes so- 
bre a relação do ser humano com suas experiências vividas, com o passado de suas memórias em face das circunstâncias do presente. Trata-se de um aspecto da seletividade da memória, diante da experiência, uma narrativa sempre será parcial.

No movimento perceptivo da imagem fotográfica, existe uma confluência entre as águas do presente e o oceano de lembranças do passado. É fundamental perceber, portanto, que os trabalhos da memória e do esquecimento moldam o terreno entre o presente do olhar e o passado da experiência. Esse é o momento do encontro entre pesquisadores, entrevistados e fotografias, momento esse compartilhado, em que tanto a personagem que está diante da câmera sendo entrevistada como os personagens que realizam a pesquisa fazem as perguntas, manuseiam a câmera, participam da construção da narrativa.

É certo que a presença de uma câmera altera a relaçáo entre entrevistador e entrevistado; do mesmo modo, a presença de um gravador ou então de um bloco de notas, cada qual apresentando suas vantagens e desvantagens. Se, por um lado, a câmera filmadora é acusada de causar constrangimento, o fato de o entrevistador náo poder olhar nos olhos do entrevistado enquanto anota algo na caderneta prejudica a relação de cumplicidade necessária para uma boa entrevista. A possibilidade de captar a expressão corporal, o tom de voz e os movimentos do olhar, entre outros, são pontos a favor do uso da câmera de vídeo. Mas uma epistemologia do registro audiovisual em pesquisas acadêmicas ainda está por se fazer, pois se trata de um recurso bastante novo comparado a outras formas seculares de comunicação (pintura, escrita, fotografia). Sobre a influência da câmera na performance dos interlocutores, concordo com o cineasta Eduardo Coutinho quando afirma:

Outra tolice que se diz há dezenas de anos é que a presença da câmera torna qualquer gesto ou fala artificial, na medida em que a simples presença da câmera - por mais bem disfarçada, por mais que o realizador more com a comunidade dez anos - muda as pessoas e, portanto, é falsa. Jean Rouch, um documentarista francês pioneiro em certos campos, já respondeu muito claramente algo óbvio: que isso que é 'verdade', em parte, não tem a menor importância porque às vezes é mais importante que a câmera catalise essa comunidade, catalise as pessoas que estáo diante dela, para que elas revelem uma 'superverdade' delas. $\mathrm{Na}$ medida em que a pessoa pode representar para a câmera, isso passa a ser interessantíssimo também. 
Como ela representa para a câmera? Que papel? Que figura? E que personagem ela quer representar para a câmera? Isto é tão interessante quanto aquilo que ela revela sem a presença da câmera. [...] não é a presença da câmera que muda realmente, o que muda é a presença de uma outra classe social, que não pertence àquele mundo e que vem interrogar sobre uma questáo. Essa possível interferência no comportamento, no gesto e na fala existe também para o historiador oral, que não tem câmera, mas tem um gravador, que pode ser um gravador de bolso, então a simples presença já muda. (Coutinho, 1997, p. 167)

Para pensarmos a crescente difusão e o interesse do grande público por documentários baseados em entrevistas, vale reler Walter Benjamin (1987) através de um outro narrador, que se conecta à sua aldeia não mais presencialmente, mas através de satélites, de projeções luminosas, cujas histórias são ouvidas e sentidas não mais em torno do tear, mas de uma tela. As narrativas agora já não são totais, mas fragmentárias. Não abordam apenas grandes mitos universais, mas mitos individuais em busca de identificaçóes. Se Walter Benjamin julgava ter desaparecido o dom de ouvir com as transformaçóes que a modernidade impôs aos afazeres cotidianos - fazendo declinar as oportunidades de narrativa e escuta presentes, por exemplo, durante a realização de um trabalho de fiar e tecer -, durante a realização de entrevistas aí está o maior exercício de sensibilidade que se impóe ao pesquisador.

A tecnologia da imagem ocupa, na contemporaneidade, uma forma central de transmissão cultural. A difusão de obras com imagens históricas representa um veículo de trânsito de informaçóes entre geraçóes, na rede das temporalidades entre passado, presente e futuro. A potencialidade educativa é fascinante para a produção de conhecimentos e a difusáo qualificada de conteúdos, no sentido da valorização do ser humano, das memórias dos trabalhadores comuns, na composição de uma obra sobre a cafeicultura que respeita e considera perspectivas de vida diferenciadas. Sáo pontos de vista de pessoas muitas vezes distantes da possibilidade de um registro histórico oficial, mas que trazem nas mãos e na lembrança uma importante história, que é a história do cotidiano, do saber fazer e dos processos relacionais da luta diária pelo trabalho.

Por fim, fica o convite para que o leitor assista a um dos documentários resultantes, o curta Café passado agora, com 10 minutos de duraçáo, 
disponível na Internet no link http://camaraclara.org.br/videos 11 cafe passado agora.htm

\section{Referências}

KOSSOY, Boris. Dicionário histórico-fotográfico brasileiro: fotógrafos e ofício da fotografia no Brasil (1833-1910). São Paulo: Instituto Moreira Sales, 2002.

KAISER, Armínio. A fotografia. In: CHOMA, Daniel; COSTA, Tati; VIEIRA, Edson Luiz (Org.). Ao sabor do café. Fotografias de Armínio Kaiser. Londrina: Câmara Clara, 2008. p.144-145.

COUTINHO, Eduardo. O cinema documentário e a escuta sensível da alteridade. Projeto História, São Paulo, n.15, abr. 1997, p.165-191.

BENJAMIN, Walter. O narrador: consideraçóes sobre a obra de Nikolai Leskov. In: Magia e técnica, arte e política: ensaios sobre literatura e história da cultura. Trad. Sergio Paulo Rouanet. São Paulo: Ed. Brasiliense, 1987. p. 197-221.

DIDI-HUBERMAN, Georges. O que vemos, o que nos olha. São Paulo: Ed. 34, 1998.

LISSOVSKY, Mauricio. O Que Fazem As Fotografias Quando Não Estamos Olhando Para Elas? In: BARRENECHEA, Miguel Angel de. (Org.). As Dobras da Memória. Rio de Janeiro: 7 Letras, 2008, p. 26-36. (Versão eletrônica enviada pelo autor, paginação 01-14).

CHOMA, Daniel. Café passado agora: narrativas em torno de fotografias de Armínio Kaiser, produzidas entre 1957 e 1970, sobre a cafeicultura no norte do Paraná. Dissertação de Mestrado. Programa de Pós Graduação em História. UDESC, Florianópolis, 2010.

VIEIRA, Edson Luiz da Silva. Sobre a luz da escuridão: memórias e sentidos presentes em acervos visuais anônimos. Dissertação de Mestrado. Programa de Pós Graduação em Comunicação visual. UEL, Londrina, 2010.

POLLAK, Michel. Memória e Identidade Social. Estudos Históricos, Rio de Janeiro, v.5, n. 10, p. 200-212, 1992.

Resumo: Uma discussão sobre a experiência do projeto audiovisual Grãos de ouro em sais de prata, documentário realizado a partir das fotografias produzidas por Armínio Kaiser, no Paraná, de 1957 a 1970 . O contato com o fotógrafo e as informaçóes de seus registros sobre a cafeicultura inspiraram, em 2008, uma pesquisa audiovisual junto a trabalhadores e ex-trabalhadores do café, a fim de registrar que narrativas seriam construídas em torno das fotografias. 
Palavras-chave: fotografia, documentário, História Oral, cafeicultura, Paraná.

\title{
Coffee images: Notes about photographs, oral history and audiovisual production
}

\begin{abstract}
A discussion about the experience of audiovisual project "Grains of gold in silver salts", documentaries made on the bases of photographs taken by Arminio Kaiser, from 1957 to 1970 , in Paraná State. The contact with the photographer and his records information about coffee growing inspired, in 2008, an audiovisual research with workers of the coffee to record narratives that would be built around photographs.
\end{abstract}

Keywords: photography, documentary, Oral History, cofee growing, Paraná State of Brazil.

Recebido em: 31/07/2012

Aprovado em: 30/08/2012 